\title{
Article
}

\section{Tungsten-Modulated Molybdenum Selenide/Graphene Heterostructure as an Advanced Electrode for All-Solid-State Supercapacitors}

\author{
Qixian Liu ${ }^{1,2,3}$, Jing Ning $1,2,3, *$, Haibin Guo ${ }^{1,2,3}$, Maoyang Xia ${ }^{1,2,3}$, Boyu Wang ${ }^{1,2,3}$, Xin Feng ${ }^{1,2,3}$, \\ Dong Wang ${ }^{1,2,3}$, Jincheng Zhang ${ }^{1,2,3}$ and Yue Hao ${ }^{1,2,3}$
}

check for

updates

Citation: Liu, Q.; Ning, J.; Guo, H.; Xia, M.; Wang, B.; Feng, X.; Wang, D.; Zhang, J.; Hao, Y. Tungsten-

Modulated Molybdenum Selenide/ Graphene Heterostructure as an Advanced Electrode for All-SolidState Supercapacitors. Nanomaterials 2021, 11, 1477. https://doi.org/ 10.3390/nano11061477

Academic Editor: Dai-Soo Lee

Received: 26 April 2021

Accepted: 31 May 2021

Published: 2 June 2021

Publisher's Note: MDPI stays neutral with regard to jurisdictional claims in published maps and institutional affiliations.
1 The State Key Discipline Laboratory of Wide Band Gap Semiconductor Technology, Xidian University, Xi'an 710071, China; lqx@stu.xidian.edu.cn (Q.L.); guohaibin0719@163.com (H.G.); maoyangxia@126.com (M.X.); wangbyxd@stu.xidian.edu.cn (B.W.); xfengk@126.com (X.F.); chankwang@xidian.edu.cn (D.W.); jchzhang@xidian.edu.cn (J.Z.); yhao@xidian.edu.cn (Y.H.)

2 Shaanxi Joint Key Laboratory of Graphene, Xidian University, Xi'an 710071, China

3 Xidian-Wuhu Research Institute, Wuhu 241000, China

* Correspondence: ningj@xidian.edu.cn

\begin{abstract}
Transition metal dichalcogenides (TMDs) have attracted widespread attention due to their excellent electrochemical and catalytic properties. In this work, a tungsten (W)-modulated molybdenum selenide $\left(\mathrm{MoSe}_{2}\right)$ /graphene heterostructure was investigated for application in electrochemistry. $\mathrm{MoSe}_{2}$ /graphene heterojunctions with low-doped W compositions were synthesized by a one-step hydrothermal catalysis approach. Based on the conducted density functional theory (DFT) calculations, it was determined that inserting a small amount of $\mathrm{W}(\approx 5 \%)$ into the $\mathrm{MoSe}_{2}$ /graphene heterostructure resulted in the modification of its lattice structure. Additionally, an increase in the distance between layers $(\approx 8 \%)$ and a decrease in the adsorption energy of the potassium ions $\left(\mathrm{K}^{+}\right)(\approx-1.08 \mathrm{eV})$ were observed following $\mathrm{W}$ doping. Overall, the electrochemical performance of the $\mathrm{MoSe}_{2}$ /graphene hybrid was enhanced by the presence of W. An all-solid-state supercapacitor device prepared using electrodes based on the W-doped $\mathrm{MoSe}_{2}$ /graphene composite achieved excellent capacitance of $444.4 \mathrm{mF} \mathrm{cm}^{-2}$ at $1 \mathrm{mV} \mathrm{s}^{-1}$. The results obtained herein revealed that the $\mathrm{MoSe}_{2}$ /graphene hybrid exhibiting low W composition could be valuable in the field of energy storage and isoelectronic doping of TMDs.
\end{abstract}

Keywords: tungsten-modulated; molybdenum selenide/graphene; all-solid-state supercapacitors

\section{Introduction}

Owing to the rapid decrease in fossil fuels and increasing energy demand, the development of simple and effective energy sources is essential [1-3]. Supercapacitors, which are considered to be excellent electrochemical energy sources, exhibit good power and energy density, high cycling life as well as rapid charge and discharge rate. Hence, they are regarded as efficient and reliable energy storage and switch devices [4-6].

Recently, transition metal dichalcogenides (TMDCs) have been used as active electrode materials in supercapacitors due to their unique properties, including a large specific surface area, layered structure, electrical conductivity, as well as thermal and chemical stabilities [7-9]. Among different TMDCs, molybdenum selenide $\left(\mathrm{MoSe}_{2}\right)$ is a particularly important material displaying a large layer spacing $(0.646 \mathrm{~nm})$, which decreases the energy barrier for adsorption/desorption of charged ions [10-12]. Nevertheless, $\mathrm{MoSe}_{2}$ tends to deform during the ion exchange process. Other limitations of this material include low electrical conductivity and cycling stability $[13,14]$. Transition metal chalcogenides/graphene hybrids have been considered in several studies [15-18] to improve the specific capacitance and cycle life of TMDCs. Notably, isoelectronic doping of TMDCs can result in the formation of ternary or quaternary alloys, which leads to changes in the physical and chemical 
properties of the materials (e.g., energy band, electrical, and optical properties) [19-21]. Previous reports show electrochemical enhancement and changes in the surface area and conductivity following isoelectronic doping [22,23].

In this work, we conducted a hydrothermal synthesis of a $\mathrm{MoSe}_{2}$ /graphene heterojunction containing a low content of tungsten $(\mathrm{W})$. The prepared material could be used as an electrode in supercapacitors and exhibited excellent potassium ion $\left(\mathrm{K}^{+}\right)$storage performance. Density functional theory (DFT) calculations were used to analyze the effect of different $\mathrm{W}$ doping concentrations on the interlayer distance and $\mathrm{K}^{+}$adsorption energy of the $\mathrm{MoSe}_{2}$ /graphene heterojunction. It was determined that the $\mathrm{W}$-doped $\mathrm{MoSe}_{2}$ electrode based on a 3D graphene framework displayed higher $\mathrm{K}^{+}$storage capacity and enhanced stability.

\section{Experimental Methods}

\subsection{Density Functional Theory}

The first principle calculation was based on DFT using the pseudopotential planewave method in the Cambridge Sequential Total Energy Package (CASTEP). The exchangecorrelation potential was described by the Perdew-Burke-Ernzerhof (PBE) functional using generalized gradient approximation (GGA). The plane-wave energy cutoff was set to $380 \mathrm{eV}$, and the Monkhorst-Pack method with G-centered $2 \times 2 \times 1 \mathrm{~K}$-points mesh was used for the Brillouin zone. The convergence criteria for the energy and force calculations were set to $2.0 \times 10^{-5} \mathrm{eV}$ per atom and $0.05 \mathrm{eV} / \AA$, respectively. The vacuum space was set to $20 \AA$.

\subsection{Growth of Graphene}

The nickel foam was sonicated in ammonium persulfate solution for $30 \mathrm{~min}$. The foam was subsequently washed with acetone, ethanol, and deionized water. The substrate for graphene growth was obtained following drying the foam under argon. Following the evacuation of the quartz tube furnace to vacuum, the nickel foam was heated from room temperature to $1000{ }^{\circ} \mathrm{C}$ under $15 \mathrm{~cm}^{3} \mathrm{~min}^{-1}$ hydrogen atmosphere. During this period, the vacuum value is about $10-100 \mathrm{~Pa}$, and the heating time was $40 \mathrm{~min}$. Then $50 \mathrm{~cm}^{3} \mathrm{~min}^{-1}$ of methane was introduced into the tube to grow graphene at $1000^{\circ} \mathrm{C}$ for $1 \mathrm{~h}$ under a mixed atmosphere. Finally, the graphene sample was quickly cooled at a rate of 200 degrees per minute.

\subsection{Preparation of a W-Doped $\mathrm{MoSe}_{2} /$ Graphene Heterostructure and $\mathrm{W}$-Doped $\mathrm{MoSe}_{2}$ Powder}

Point three grams of $\mathrm{Na}_{2} \mathrm{MoO}_{4} \cdot 2 \mathrm{H}_{2} \mathrm{O}, 0.3 \mathrm{~g}$ of $\left(\mathrm{NH}_{4}\right)_{5} \mathrm{H}_{5}\left[\mathrm{H}_{2}\left(\mathrm{WO}_{4}\right)_{6}\right] \cdot \mathrm{H}_{2} \mathrm{O}$, and $0.2 \mathrm{~g}$ of Se were mixed with 5-10 mL of $\mathrm{N}_{2} \mathrm{H}_{4} \cdot \mathrm{H}_{2} \mathrm{O}$ and stirred for $15 \mathrm{~min}$. (All chemicals are purchased from Kequan Laboratory Co., Ltd., Xi'an, China) Fifty milliliters of deionized water was added, and the solution was stirred for $15 \mathrm{~min}$. After mixing, the mixture was divided into two equal parts and transferred to two $60 \mathrm{~mL}$ Teflon-lined stainless steel autoclaves. The prepared nickel foam/graphene was subsequently placed in one of them. The mixture was heated to $160{ }^{\circ} \mathrm{C}$ for $24 \mathrm{~h}$. The sample containing the nickel foam/graphene was then taken out and washed several times with deionized water and ethanol. The sample was dried at $80^{\circ} \mathrm{C}$ for $24 \mathrm{~h}$ under a vacuum. Ten milliliters of the reaction solution was added into another container, centrifuged, and ultrasonicated. At the same time, different Mo: $\mathrm{W}$ ratios $(1: 1,1: 2,2: 1)$ and various temperatures $\left(140{ }^{\circ} \mathrm{C}\right.$, $150{ }^{\circ} \mathrm{C}, 170{ }^{\circ} \mathrm{C}, 180{ }^{\circ} \mathrm{C}$ ) were investigated to study the impact on the performance of composite electrodes.

\subsection{Characterization of Materials}

The W-doped $\mathrm{MoSe}_{2}$ /graphene nanostructures were investigated by SEM (Quanta 600FEG, FEI, Hillsboro, OH, USA). The crystallinity of the materials was evaluated by highresolution XRD (D8 Discovery, Bruker, Berlin, Germany) analysis in the Bragg (reflection) geometry with a pure $\mathrm{Cu} \mathrm{k}_{\alpha 1}$ radiation (wavelength; $\lambda ; 1.54056 \AA$ ). The Raman spectrum 
was obtained with a Raman spectroscopy system (Lab Ram HR 800, Horiba JY, Kuoto, Japan) with an $\mathrm{Ar}^{+}$laser (514 nm wavelength) as the excitation source. The elemental analysis of the composite was conducted by XPS (ESCALAB, 250Xi, ThermoFisher Scientific, Waltham, MA, USA).

\subsection{Preparation of the Electrolyte}

Five grams of PVA (polyvinyl alcohol ) was added to $35 \mathrm{~mL}$ of deionized water. The solution was stirred in a water bath at $80{ }^{\circ} \mathrm{C}$ until the PVA was completely dissolved. Subsequently, $5 \mathrm{~g}$ of $\mathrm{KOH}$ was dissolved in $5 \mathrm{~mL}$ of deionized water. The $\mathrm{KOH}$ solution was slowly added to the solution of PVA and stirred.

\subsection{Electrochemical Analysis}

A three-electrode test system was used for the electrochemical measurements. The system was composed of an active material as the working electrode, $\mathrm{Ag} / \mathrm{AgCl}$ as the reference electrode, platinum mesh as the counter electrode, and $3 \mathrm{M} \mathrm{KOH}$ as the electrolyte. For the electrochemical measurements of the all-solid-state supercapacitors, the electrodes and cellulose membrane were stacked in a sequence. The active material was in direct contact with the current collector. The electrolyte employed for the analysis was PVA-KOH. $\mathrm{CV}$ was conducted at a scan rate of 1 to $50 \mathrm{mV} \mathrm{s}^{-1}$. Constant current charging/discharging was performed at a current density of 0.5 to $8 \mathrm{~mA} \mathrm{~cm}^{-2}$. EIS was conducted in the frequency range of $0.01 \mathrm{~Hz}$ to $100 \mathrm{kHz}$ with a disturbance of $5 \mathrm{mV}$ (rms) under open-circuit voltage.

For the CV curves, the specific capacitance values were calculated using Equation (1):

$$
\mathrm{C}_{\mathrm{S}}=\frac{\int \mathrm{I}(\mathrm{V}) \mathrm{dv}}{v \mathrm{~S} \Delta \mathrm{V}}\left(\mathrm{mF} \mathrm{cm}^{-2}\right)
$$

where $S$ refers to the working area of the supercapacitor $\left(\mathrm{cm}^{2}\right), V$ indicates the scan rate $\left(\mathrm{vs}^{-1}\right)$, and $\triangle \mathrm{V}$ is the potential window $(\mathrm{V})$.

For the GCD curves, the specific capacitance was calculated according to Equation (2):

$$
\mathrm{C}_{\mathrm{S}}=\frac{\mathrm{I} \Delta \mathrm{t}}{\mathrm{S} \Delta \mathrm{V}}\left(\mathrm{mF} \mathrm{cm}^{-2}\right)
$$

where $\mathrm{I}$ is the discharge current $(\mathrm{mA})$ and $\triangle \mathrm{t}$ denotes the discharge time (s).

The energy density and power density of the supercapacitor cell were obtained using Equations (3) and (4):

$$
\begin{gathered}
\mathrm{E}=\frac{\mathrm{C}_{\mathrm{s}} \Delta \mathrm{V}^{2}}{2}\left(\mathrm{mWh} \mathrm{cm}^{-2}\right) \\
\mathrm{P}=\frac{\mathrm{E}}{\Delta \mathrm{t}}\left(\mathrm{mW} \mathrm{cm}^{-2}\right)
\end{gathered}
$$

where E refers to the energy density $\left(\mathrm{mWh} \mathrm{cm}^{-2}\right)$, P indicates the power density $\left(\mathrm{mW} \mathrm{cm}^{-2}\right)$, and $\Delta \mathrm{t}(\mathrm{s})$ is the total discharge duration.

\section{Results and Discussion}

The structures of $\mathrm{MoSe}_{2}$ /graphene containing low $\mathrm{W}$ contents are illustrated in Figure 1a. W atoms were used to replace Mo in the $3 \times 3 \times 1$ supercell of $\mathrm{MoSe}_{2}$. When the Mo atoms were substituted by $\mathrm{W}$, the doping concentration of $\mathrm{W}$ was $5.6 \%$, which was consistent with the results obtained by X-ray photoelectron spectroscopy (XPS) (5\%). Figure $1 \mathrm{~d}$ shows the interlayer distance and $\mathrm{K}^{+}$adsorption energy of $\mathrm{MoSe}_{2} /$ graphene doped with different concentrations of $W(5.6 \%, 11.1 \%, 16.7 \%$, and $22.2 \%)$. Compared with pure $\mathrm{MoSe}_{2}$ /graphene, $\mathrm{MoSe}_{2}$ /graphene doped with W at a concentration of $5.6 \%$ exhibited a larger interlayer distance $(\approx 8 \%, 12.22 \AA)$ and smaller $\mathrm{K}^{+}$adsorption energy 
$(-1.08 \mathrm{eV})$. This facilitated the process of $\mathrm{K}^{+}$adsorption/extraction. The adsorption energy of $\mathrm{K}$ ions $\left(\mathrm{E}_{\mathrm{a}}\right)$ is determined by Equation (5):

$$
\mathrm{E}_{\mathrm{a}}=\frac{\mathrm{E}_{\text {total energy after inserting Kions }}-\mathrm{E}_{\text {total energy before inserting } \mathrm{K} \text { ions }}-\mathrm{nE}_{\mathrm{K}} \text { ions }}{\mathrm{n}}
$$

where, the insertion energy of $\mathrm{K}$ ions between different layers at different $\mathrm{W}$ doping concentrations is shown in Figure S1. The adsorption energy of $\mathrm{K}$ ions between W-doped $\mathrm{MoSe}_{2}$ and graphene is higher than that between W-doped $\mathrm{MoSe}_{2}$. This may be the interlayer distance between graphene and $\mathrm{W}$-doped $\mathrm{MoSe}_{2}(\approx 5.6 \AA)$ is smaller than that between tungsten-doped molybdenum selenide, making it more difficult for potassium ions to insert/detach.

a
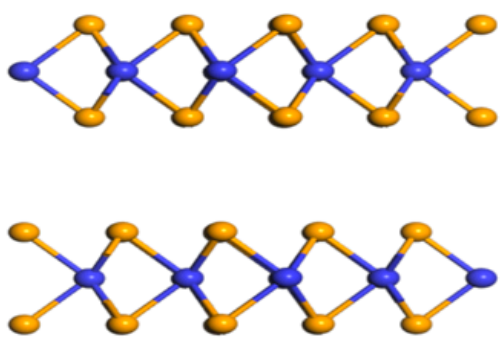

C
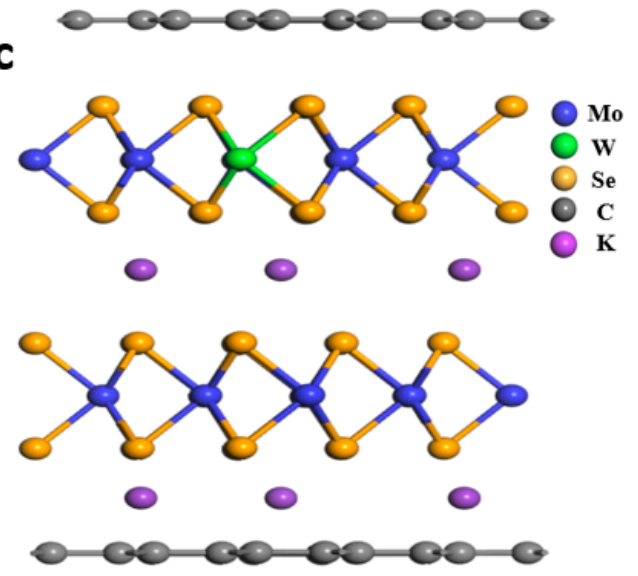

b
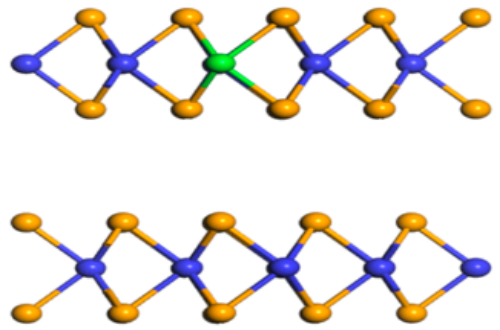

d

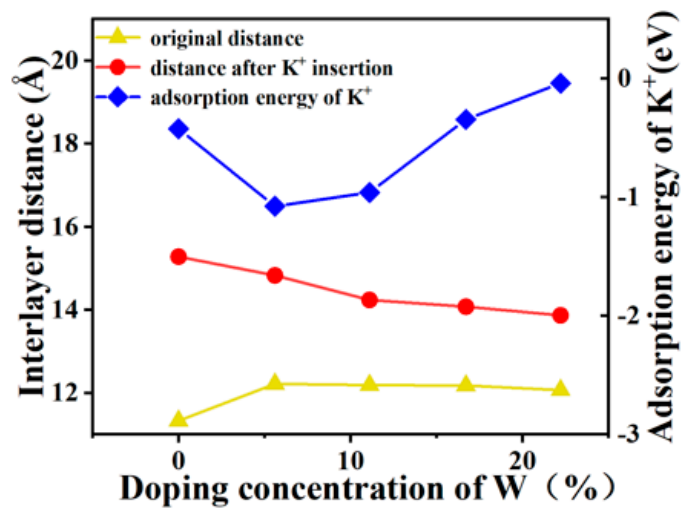

Figure 1. (a) Side view of $\mathrm{MoSe}_{2}$ /graphene. (b) Side view of $\mathrm{MoSe}_{2}$ /graphene containing $5.6 \% \mathrm{~W}$. (c) Side view of $\mathrm{MoSe}_{2}$ /graphene containing $5.6 \% \mathrm{~W}$ and intercalated $\mathrm{K}^{+}$ions. Orange balls represent Se atoms, blue balls indicate Mo atoms, the green ball refers to the $\mathrm{W}$ atom, and purple balls show potassium ions. (d) Interlayer distance of pure $\mathrm{MoSe}_{2}$ /graphene and $\mathrm{MoSe}_{2}$ /graphene doped with different concentrations of $\mathrm{W}$, interlayer distance in the presence of $\mathrm{K}^{+}$ intercalation in $\mathrm{MoSe}_{2}$ /graphene and $\mathrm{MoSe}_{2}$ /graphene doped with different concentrations of W, adsorption energy of $\mathrm{K}^{+}$ on $\mathrm{MoSe}_{2}$ /graphene and $\mathrm{MoSe}_{2}$ /graphene doped with different concentrations of W.

Scanning electron microscopy (SEM) and energy dispersive spectrometry (EDS) were used to characterize the $\mathrm{W}$-doped $\mathrm{MoSe}_{2}$ /graphene nanostructures (Figure $2 \mathrm{a}-\mathrm{c}$ ). It was determined that the graphene films prepared by low-pressure chemical vapor deposition (LPCVD) were stacked on the framework of the nickel foam (Figure 2a), while the Wdoped $\mathrm{MoSe}_{2}$ particles grown on graphene assembled to form nanoballs and nanoflowers (Figure 2b,c). The composite structures of W-doped $\mathrm{MoSe}_{2} /$ graphene closely interacted with each other. The potential structures of W-doped $\mathrm{MoSe}_{2}$ and graphene are demonstrated in Figure 2b. Moreover, the EDS images of W-doped $\mathrm{MoSe}_{2}$ /graphene nanostructures revealed the presence of Mo, W, and Se. Through SEM, we observed that the presence of graphene not only provides a framework for the growth of W-doped $\mathrm{MoSe}_{2}$ 
materials but also enhances the electrical conductivity and contact area of the composite material, thereby providing more active sites. The nanoflower structure of $\mathrm{W}$-doped $\mathrm{MoSe}_{2}$ is uniformly grown on the graphene framework, providing a larger surface area and a shorter ion channel during charge and discharge. The two materials complement each other and enhance the electrochemical performance of the composite material.
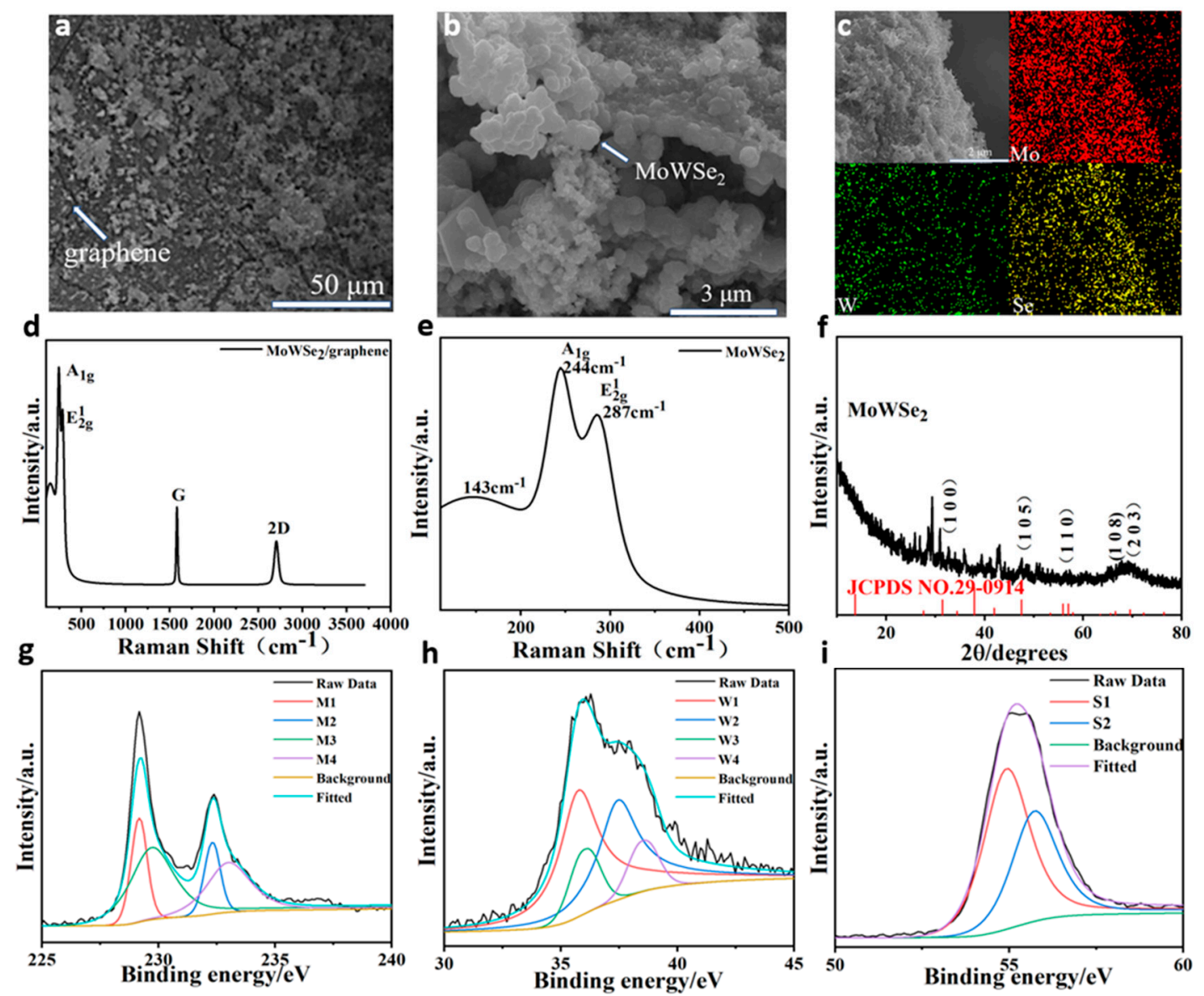

Figure 2. (a-c) SEM images of W-doped $\mathrm{MoSe}_{2}$ /graphene and EDS images of W-doped MoSe 2 /graphene. (d,e) Raman spectra of W-doped $\mathrm{MoSe}_{2}$ /graphene. (f) XRD patterns of W-doped MoSe $e_{2}$ (g-i) XPS survey spectra of W-doped MoSe 2 (Mo 3d, W 4f, and Se 3d).

The outcomes of the Raman spectroscopy analysis of W-doped $\mathrm{MoSe}_{2} /$ graphene nanostructures are shown in Figure 2d,e. The peaks at 1580.7 and $2705.0 \mathrm{~cm}^{-1}$ corresponded to the $\mathrm{G}$ and $2 \mathrm{D}$ bands of graphene, respectively. In addition, the signals at 244.2 and $287.5 \mathrm{~cm}^{-1}$ were attributed to the $\mathrm{A}_{1 \mathrm{~g}}$ and $\mathrm{E}_{2 \mathrm{~g}}{ }^{1}$ modes, correspondingly. A slight shift of the peaks to the lower wavenumbers compared to those of pure $\mathrm{MoSe}_{2}$ confirmed the successful doping of $\mathrm{W}$ in $\mathrm{MoSe}_{2}$ [24]. The spectral data and SEM images of the raw graphene are shown in Figures S2 and S3. The results of the X-ray diffraction (XRD) evaluation are demonstrated in Figure 2f. The characteristic peaks at $30.9^{\circ}, 47.5^{\circ}, 55.5^{\circ}, 66.6^{\circ}$, and $69.6^{\circ}$

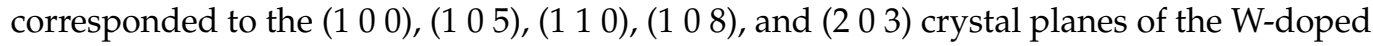
$\mathrm{MoSe}_{2}$ nanostructure, respectively. The detected peaks were comparable to those of pure $\mathrm{MoSe}_{2}$; however, a small shift to lower values was noted. The particle size of the powdered samples was not uniform enough, and there were some by-products in the hydrothermal synthesis, resulting in a lot of XRD data miscellaneous peaks, such as $\mathrm{Mo}_{3} \mathrm{Se}_{4}, \mathrm{Mo}_{15} \mathrm{Se}_{19}$, and Se rings [25]. Therefore, we tested $\mathrm{W}$-doped $\mathrm{MoSe}_{2} /$ graphene/Ni foam electrode samples. The electrode was washed several times with ethanol and deionized water and dried in a vacuum oven at $60^{\circ} \mathrm{C}$ for $12 \mathrm{~h}$, in order to obtain a well-crystallized product. 
The prepared materials are shown in Figure S4. We observe peaks at $25.73^{\circ}, 31.8^{\circ}, 33.6^{\circ}$,

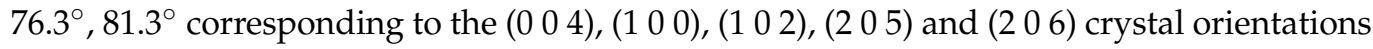
of $\mathrm{MoSe}_{2}$ (PDF\#29-0914). A slight shift in the peaks to the lower wavenumbers compared to those of pure $\mathrm{MoSe}_{2}$ confirmed doping of $\mathrm{W}$ in $\mathrm{MoSe}_{2}$. The peaks at $43.3^{\circ}, 51.8^{\circ}$, and $81.4^{\circ}$

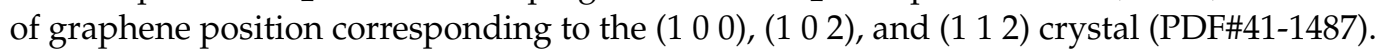
Furthermore, XPS was employed to investigate the elemental composition of the W-doped $\mathrm{MoSe}_{2}$ nanostructure (Figure 2g-i). The Mo $3 \mathrm{~d}$ peaks attributed to $\mathrm{Mo}^{+4} 3 \mathrm{~d} 5 / 2$ and $\mathrm{Mo}^{+4}$ $3 \mathrm{~d} 3 / 2$ were detected at 229.2 and $232.4 \mathrm{eV}$, respectively, and were comparable to those of bulk $\mathrm{MoS}_{2}$ and $\mathrm{MoSe}_{2}$. Similarly, the W 4f peaks could be divided into W 4f $7 / 2$ and W $4 \mathrm{f} 5 / 2$ at the binding energies of 35.8 and $36.3 \mathrm{eV}$ (W1 and W2, respectively) (Figure 2h). The ratios of the characteristic peak areas of different elements to the corresponding atomic sensitivity factors were normalized to calculate that the doping concentration of $\mathrm{W}$ atomic percentage of the element is about $5.6 \%$. It is noted that the peaks at $230 \mathrm{eV}$ (M3) and $233 \mathrm{eV}$ (M4) can be separately attributed to +3 and +6 oxidation state of Mo, due to the oxidation in the hydrothermal synthesis process. The peaks of W1 and W2 shifted to the direction of high energy by about $2 \mathrm{eV}$. This may be due to the loss of electrons from $\mathrm{W}$ during the formation of Mo-W bonding. In addition, the peaks at higher binding energy $37 \mathrm{eV}(\mathrm{W} 3)$ and $38 \mathrm{eV}(\mathrm{W} 4)$ can be assigned to the bonding of Mo-W and tungsten oxides. Owing to the spin-orbit coupling, the $3 \mathrm{~d}$ peaks of Se (Figure 2i) could be assigned to the $3 \mathrm{~d} 5 / 2$ and $3 \mathrm{~d} 3 / 2$ states at 54.9 and $55.7 \mathrm{eV}$, respectively [26].

The electrochemical performance of W-doped $\mathrm{MoSe}_{2}$ /graphene electrodes was evaluated by cyclic voltammetry (CV), galvanostatic charge-discharge (GCD), and electrochemical impedance spectroscopy (EIS) using $3 \mathrm{M} \mathrm{KOH}$ as the electrolyte. Different ratios of raw materials (mMo:mW $=1: 1,1: 2$, and 2:1), growth time $(12,18,24,30$, and $36 \mathrm{~h}$ ), and temperature $\left(140{ }^{\circ} \mathrm{C}, 150{ }^{\circ} \mathrm{C}, 160{ }^{\circ} \mathrm{C}, 170{ }^{\circ} \mathrm{C}\right.$, and $\left.180{ }^{\circ} \mathrm{C}\right)$ were tested to achieve the most optimal conditions for the growth the W-doped $\mathrm{MoSe}_{2}$ /graphene heterostructure. Figure 3a illustrates the CV curves at a scan rate of $50 \mathrm{mV} \mathrm{s}^{-1}$. The largest area of mMo:mW $=1: 1$ under the CV curve of the electrode indicated the highest capacitance. Figure $3 \mathrm{~b}$ compares different GCD curves at a growth temperature from $140{ }^{\circ} \mathrm{C}$ to $180{ }^{\circ} \mathrm{C}$ at $0.5 \mathrm{~A} \mathrm{~g}^{-1}$. The electrode grown at $160^{\circ} \mathrm{C}$ displayed a longer discharge time, suggesting higher capacitance. Moreover, varying the growth time of the electrode demonstrated that the best results were achieved after $24 \mathrm{~h}$. The material obtained after this time exhibited the largest capacitance (Figure 3c). Figure 3d shows the CV curves of W-doped $\mathrm{MoSe}_{2} /$ graphene electrodes in the voltage range from -0.3 to $0.7 \mathrm{~V}$ at various scan rates. The presence of obvious symmetric redox peaks indicated the occurrence of a typical Faradaic process involving oxidation/reduction reactions. Similar shapes and broadening peaks were also be observed at higher scan rates, implying good performance. The GCD measurements were performed between -0.2 and $0.4 \mathrm{~V}$ at current densities ranging from 0.5 to $8 \mathrm{~A} \mathrm{~g}^{-1}$ (Figure 3e). W-doped $\mathrm{MoSe}_{2}$ /graphene showed capacitance of 296, 245, 197,155 , and $114 \mathrm{~F} \mathrm{~g}^{-1}$ at a current density of $0.5,1,2,4$, and $8 \mathrm{~A} \mathrm{~g}^{-1}$, respectively. The EIS data summarized in Figure 3f suggested that W-doped $\mathrm{MoSe}_{2}$ /graphene exhibited series resistance of $0.67 \mathrm{ohm}$ and contact resistance of $0.2 \mathrm{ohm}$, which accelerated the electrostatic adsorption of ions. According to Figure 3d, the CV curve shows symmetric redox peaks. This indicates that there were non-Faraday and Faraday processes in the composite electrode. The Faraday process of adsorption/desorption of potassium ions at the active sites on the surface and the Faraday process of oxidation/reduction occurred in the internal nanostructure. The possible reactions are expressed by the following equations:

$$
\begin{gathered}
\mathrm{Mo}(\mathrm{W}) \mathrm{Se}_{2}+\mathrm{K}^{+}+\mathrm{e}^{-} \rightarrow \mathrm{Mo}(\mathrm{W}) \mathrm{Se}_{2}-\mathrm{K} \text { (surface process) } \\
\mathrm{Mo}(\mathrm{W}) \mathrm{Se}_{2}+\mathrm{K}^{+}+\mathrm{e}^{-} \rightarrow \mathrm{KMo}(\mathrm{W}) \mathrm{Se}_{2} \text { (redox process) }
\end{gathered}
$$



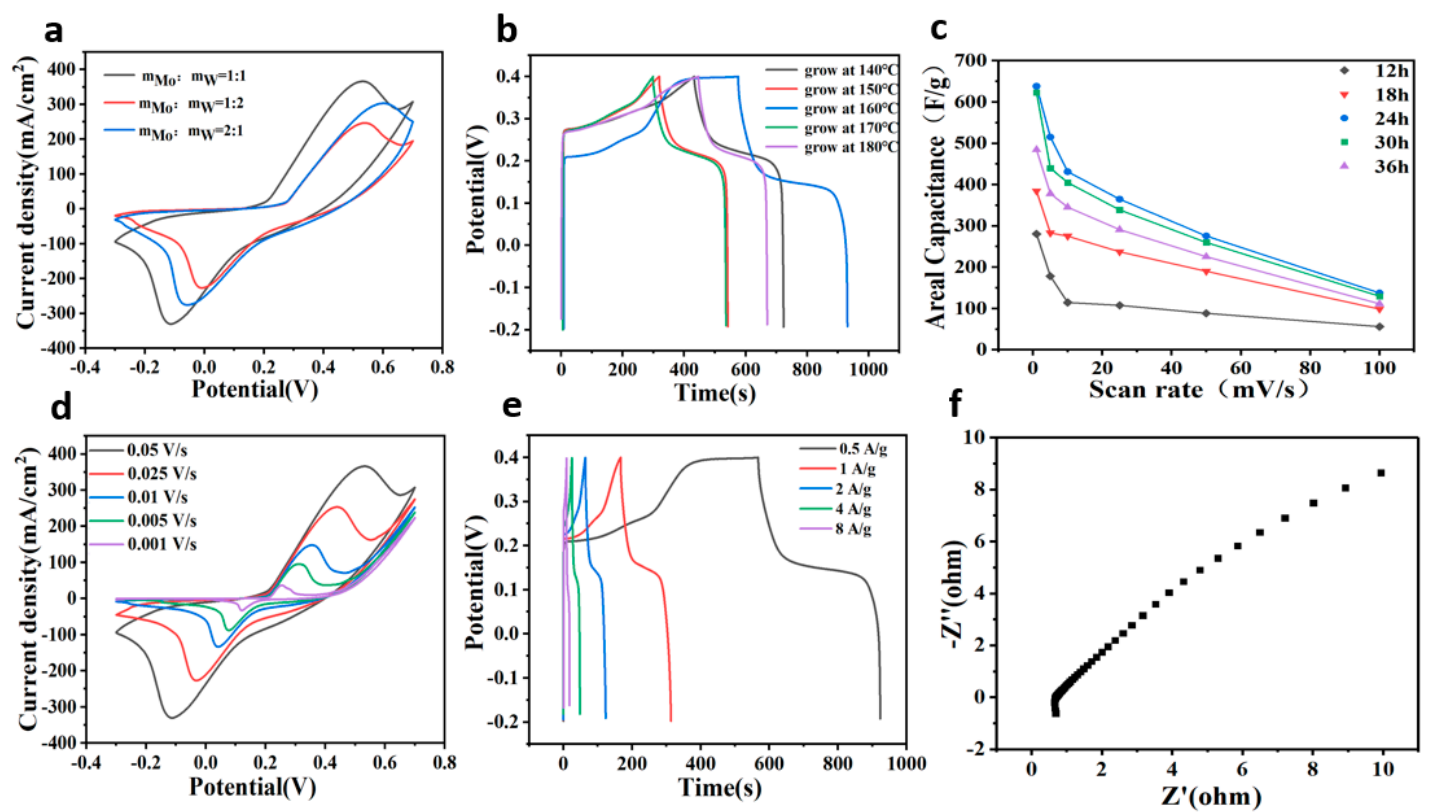

Figure 3. (a) CV curves of W-doped $\mathrm{MoSe}_{2}$ /graphene electrodes with a different molar mass ratio at $50 \mathrm{mV} \mathrm{s}^{-1}$. (b) GCD curves of W-doped $\mathrm{MoSe}_{2}$ /graphene electrodes at various growth temperatures at $0.5 \mathrm{~A} \mathrm{~g}^{-1}$. (c) Areal capacitance of W-doped $\mathrm{MoSe}_{2}$ /graphene electrodes at a different growth time. (d) CV curves of W-doped $\mathrm{MoSe}_{2} /$ graphene electrodes at different scan rates. (e) GCD curves of W-doped $\mathrm{MoSe}_{2}$ /graphene electrodes at various current densities. (f) Nyquist plots of $\mathrm{W}$-doped $\mathrm{MoSe}_{2}$ /graphene electrodes.

A symmetrical all-solid-state supercapacitor was assembled using a polyvinyl alcohol (PVA)-KOH electrolyte and $\mathrm{W}$-doped $\mathrm{MoSe}_{2}$ /graphene electrode to investigate its energy storage behavior. Figure 4 a demonstrates the $\mathrm{CV}$ curves of the all-solid-state supercapacitor in a voltage window of $0-0.9 \mathrm{~V}$. No redox peaks were detected at different scanning rates with symmetrical cathode and anode, which indicated equal capacitance during charge and discharge. This implied that the all-solid-state supercapacitor was a Faraday quasi-capacitor. The capacitance was established to be 444.4, 266.7, 211.1, 182.2, and $157.8 \mathrm{mF} \mathrm{cm}^{-2}$ at a scanning rate of $1,5,10,25$, and $50 \mathrm{mV} \mathrm{s}^{-1}$, respectively. Figure $4 \mathrm{~b}$ shows the GCD curve of the all-solid-state supercapacitor. The capacitance was equal to $60.5,56.2,51.0,44.7$, and $34.7 \mathrm{mF} \mathrm{cm}^{-2}$ at a current density of $0.5,1,2,4$, and $8 \mathrm{~mA} \mathrm{~cm}^{-2}$. The charge and discharge curves were roughly equal, indicating that the supercapacitor exhibited excellent energy storage properties. Furthermore, Figure $4 \mathrm{c}$ demonstrates the Nyquist plots of the all-solid-state supercapacitor based on W-doped $\mathrm{MoSe}_{2}$ /graphene. The equivalent series resistance of the supercapacitor was determined at $0.9 \mathrm{ohm}$, while the charge transfer resistance was approximately $0.5 \mathrm{ohm}$. Figure $4 \mathrm{~d}$ shows the cycle lifetime of the all-solid-state supercapacitor based on W-doped $\mathrm{MoSe}_{2} /$ graphene at $500 \mathrm{mV} \mathrm{s}^{-1}$. Notably, $81.3 \%$ of the capacitance was retained after 5000 cycles. The SEM of the device after 5000 cycles was tested shown in Figure S5. It can be observed that the active material was reduced, part of it falls off, and there were cracks on the surface to expose the graphene. This was also the reason for the reduced capacitance and performance of the device after multiple cycles. The Ragone plot of the all-solid-state supercapacitor based on Gra/Wdoped $\mathrm{MoSe}_{2}$ is illustrated in Figure 4e. The W-doped $\mathrm{MoSe}_{2}$ /graphene all-solid-state supercapacitor exhibited an energy density of $0.003 \mathrm{mWh} \mathrm{cm}^{-2}$ at a power density of $0.15 \mathrm{~mW} \mathrm{~cm}{ }^{-2}$. Compared to other previously reported all-solid-state supercapacitors, the electrode based on W-doped $\mathrm{MoSe}_{2}$ /graphene heterostructure showed enhanced properties (Figure 4f) [27-33]. The combined action of the W-doped $\mathrm{MoSe}_{2} /$ graphene heterostructure and the all-solid-state electrolyte resulted in excellent electrochemical performance. 
a

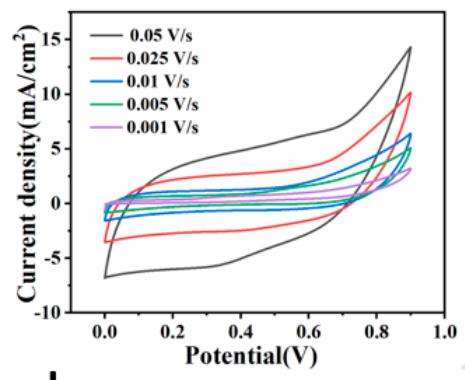

d

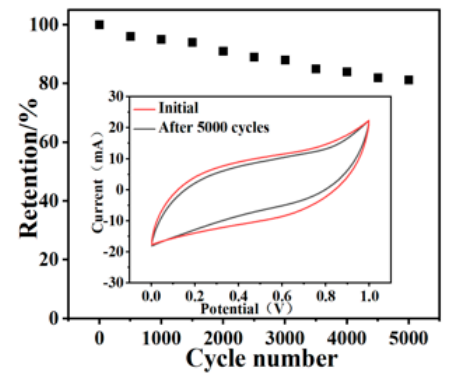

b
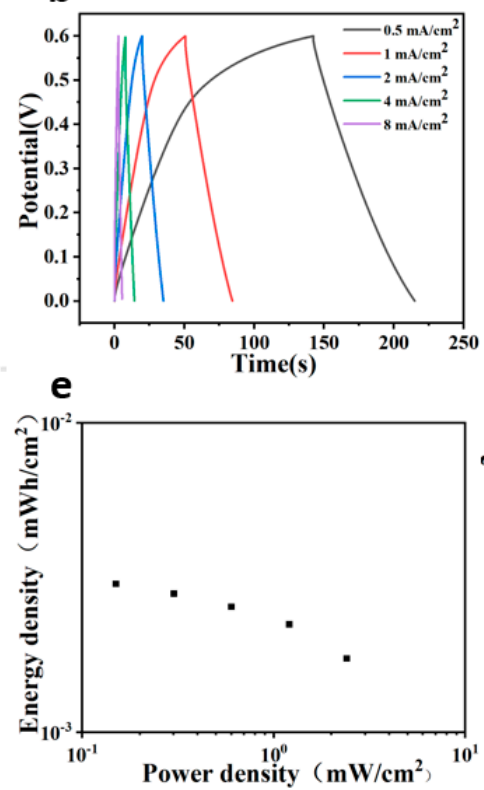

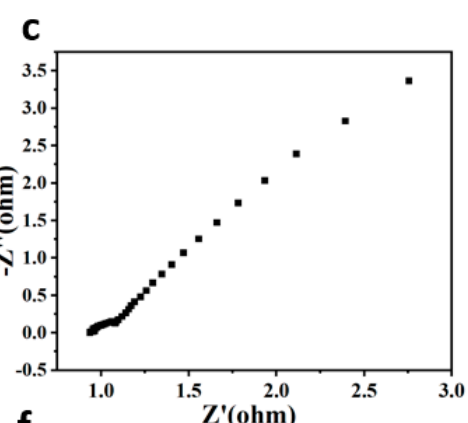

f

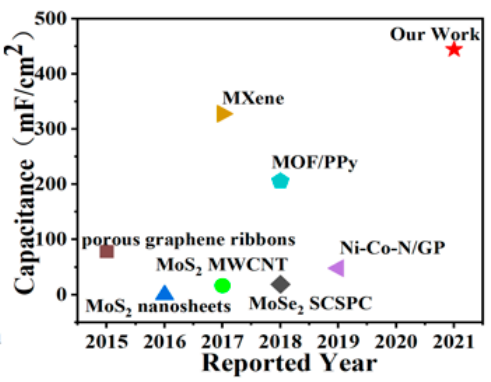

Figure 4. (a) CV curves of the all-solid-state supercapacitor based on W-doped $\mathrm{MoSe}_{2}$ /graphene at different scan rates. (b) GCD curves of the all-solid-state supercapacitor based on W-doped $\mathrm{MoSe}_{2} /$ graphene at various current densities. (c) Nyquist plots of the all-solid-state supercapacitor based on W-doped $\mathrm{MoSe}_{2}$ /graphene. (d) Cycle lifetime of the all-solidstate supercapacitor based on W-doped $\mathrm{MoSe}_{2}$ /graphene at $500 \mathrm{mV} \mathrm{s}^{-1}$. (e) Ragone plot of the all-solid-state supercapacitor based on W-doped $\mathrm{MoSe}_{2}$ /graphene. (f) Plot of the gravimetric capacitance of W-doped $\mathrm{MoSe}_{2}$ /graphene compared to other previously reported 2D electrode materials.

\section{Conclusions}

In conclusion, $\mathrm{MoSe}_{2}$ /graphene heterostructures containing low contents of W were successfully prepared by a catalytic hydrothermal method. DFT calculations were used to evaluate the characteristics of W-doped $\mathrm{MoSe}_{2}$ /graphene, which exhibited a large interlayer distance and low $\mathrm{K}^{+}$adsorption energy. This facilitated electrochemical reactions. Moreover, electrochemical investigations demonstrated that all-solid-state supercapacitors based on the $\mathrm{MoSe}_{2}$ /graphene heterostructure displayed excellent supercapacitor performance. Specific capacity of $444.4 \mathrm{mF} \mathrm{cm}^{-2}$ was achieved at a scanning rate of $1 \mathrm{mV} \mathrm{s}^{-1}$. Notably, $81.3 \%$ of capacitance was retained after 5000 cycles at $500 \mathrm{mV} \mathrm{s}^{-1}$.

Supplementary Materials: The following are available online at https:/ /www.mdpi.com/article/ 10.3390/nano11061477/s1, Figure S1: Adsorption energy of K ions under different doping concentrations. Figure S2: Raman spectra of graphene. Figure S3: SEM image of graphene. Figure S4: (a) XRD spectrum of Graphene/Ni foam, (b) XRD spectrum of Mo:W = 1:1, (c) XRD spectrum of Mo:W = 1:2, (d) XRD spectrum of Mo:W = 2:1, (e) XRD spectrum of sample grown at $140^{\circ} \mathrm{C}$, (f) $\mathrm{XRD}$ spectrum of sample grown at $150{ }^{\circ} \mathrm{C}$, (g) XRD spectrum of sample grown at $170{ }^{\circ} \mathrm{C}$, (h) XRD spectrum of sample grown at $180^{\circ} \mathrm{C}$. Figure S5: SEM image of device after 5000 cycles.

Author Contributions: Conceptualization, M.X.; Data curation, Q.L.; Formal analysis, Q.L.; Funding acquisition, D.W., J.Z. and Y.H.; Investigation, X.F.; Methodology, H.G.; Software, B.W.; Writingoriginal draft, Q.L.; Writing-review \& editing, J.N. All authors have read and agreed to the published version of the manuscript.

Funding: This research was funded by the Natural Science Basic Research Plan in Shaanxi Province of China (2017ZDCXL-GY-11-03, 2019ZDLGY16-02); Youth Science and Technology Nova Program of Shaanxi Province (2020KJXX-068); Wuhu and Xidian University special fund for industry-universityresearch cooperation (HX01201909039).

Institutional Review Board Statement: Not applicable. 
Informed Consent Statement: Not applicable.

Data Availability Statement: The data presented in this study are available from the corresponding author.

Acknowledgments: The authors extend their appreciation to the reviewers and the editorial team of Nanomaterials for constructive comments and guidance.

Conflicts of Interest: The authors declare that they have no known competing financial interests or personal relationships that could have appeared to influence the work reported in this paper.

\section{References}

1. Turner, J.A. A realizable renewable energy future. Science 1999, 285, 687-689. [CrossRef]

2. Lund, H. Renewable energy strategies for sustainable development. Energy 2007, 32, 912-919. [CrossRef]

3. Dincer, I. Renewable energy and sustainable development: A crucial review. Renew. Sustain. Energy Rev. 2000, 4, 157-175. [CrossRef]

4. Zhang, L.L.; Zhao, X.S. Carbon-based materials as supercapacitor electrodes. Chem. Soc. Rev. 2009, 38, 2520-2531. [CrossRef]

5. Wang, Y.; Shi, Z.; Huang, Y.; Ma, Y.; Wang, C.; Chen, M.; Chen, Y. Supercapacitor devices based on graphene materials. J. Phys. Chem. C 2009, 113, 13103-13107. [CrossRef]

6. Frackowiak, E. Carbon materials for supercapacitor application. Phys. Chem. Chem. Phys. 2007, 9, 1774-1785. [CrossRef] [PubMed]

7. Cherusseri, J.; Choudhary, N.; Sambath Kumar, K.S.; Jung, Y.; Thomas, J. Recent trends in transition metal dichalcogenide based supercapacitor electrodes. Nanoscale Horiz. 2019, 4, 840-858. [CrossRef]

8. Seman, R.N.A.R.; Azam, M.A.; Ani, M.H. Graphene/transition metal dichalcogenides hybrid supercapacitor electrode: Status, challenges, and perspectives. Nanotechnology 2018, 29, 502001. [CrossRef]

9. Lin, L.; Lei, W.; Zhang, S.; Liu, Y.; Wallace, G.G.; Chen, J. Two-dimensional transition metal dichalcogenides in supercapacitors and secondary batteries. Energy Storage Mater. 2019, 19, 408-423. [CrossRef]

10. Balasingam, S.K.; Lee, J.S.; Jun, Y. Few-layered $\mathrm{MoSe}_{2}$ nanosheets as an advanced electrode material for supercapacitors. Dalton Trans. 2015, 44, 15491-15498. [CrossRef]

11. Zhao, X.; Cai, W.; Yang, Y.; Song, X.; Neale, Z.; Wang, H.; Sui, J.; Cao, G. MoSe 2 nanosheets perpendicularly grown on graphene with Mo-C bonding for sodium-ion capacitors. Nano Energy 2018, 47, 224-234. [CrossRef]

12. Guo, H.; Ning, J.; Wang, B.; Feng, X.; Xia, M.; Wang, D.; Jia, Y.; Zhang, J.; Hao, Y. Sodium ion-intercalated nanoflower 1T-2H $\mathrm{MoSe}_{2}$-graphene nanocomposites as electrodes for all-solid-state supercapacitors. J. Alloys Compd. 2021, 853, 157116. [CrossRef]

13. Xia, M.; Ning, J.; Wang, D.; Feng, X.; Wang, B.; Guo, H.; Zhang, J.; Hao, Y. Ammonia-assisted synthesis of gypsophila-like $1 \mathrm{~T}-\mathrm{WSe}_{2}$ /graphene with enhanced potassium storage for all-solid-state supercapacitor. Chem. Eng. J. 2021, 405, 126611. [CrossRef]

14. El-Mahalawy, S.H.; Evans, B.L. Temperature dependence of the electrical conductivity and hall coefficient in $2 \mathrm{H}-\mathrm{MoS}_{2}, \mathrm{MoSe}_{2}$, $\mathrm{WSe}_{2}$, and $\mathrm{MoTe}_{2}$. Phys. Stat. Sol. 1977, 79, 713-722. [CrossRef]

15. Lin, T.W.; Sadhasivam, T.; Wang, A.Y.; Chen, T.; Lin, J.; Shao, L. Ternary composite nanosheets with $\mathrm{MoS}_{2} / \mathrm{WS}_{2} / \mathrm{Graphene}$ heterostructures as high-performance cathode materials for supercapacitors. Chem Electro Chem 2018, 5, 1024-1031. [CrossRef]

16. Wang, H.; Feng, H.; Li, J. Graphene and graphene-like layered transition metal dichalcogenides in energy conversion and storage. Small 2014, 10, 2165-2181. [CrossRef]

17. Bissett, M.A.; Kinloch, I.A.; Dryfe, R.A.W. Characterization of $\mathrm{MoS}_{2}$-graphene composites for high-performance coin cell supercapacitors. ACS Appl. Mater. Interfaces 2015, 7, 17388-17398. [CrossRef] [PubMed]

18. Abraham, A.M.; Bharath, G.; Hai, A.; Banat, F. Preparation of $\mathrm{MoS}_{2}$ /graphene nanostructures and their supercapacitor and hydrogen evolution reaction (HER) performances. J. Phys. D 2019, 53, 065501. [CrossRef]

19. Zhao, Y.; Wang, W.; Li, C.; He, L. First-principles study of nonmetal doped monolayer $\mathrm{MoSe}_{2}$ for tunable electronic and photocatalytic properties. Sci. Rep. 2017, 7, 1. [CrossRef] [PubMed]

20. Zhao, Y.; Wang, W.; Li, C.; He, L. Tuning the magnetic properties of the monolayer MoSe 2 by nonmetal doping: First-principles study. Solid State Commun. 2018, 281, 6-11. [CrossRef]

21. Ma, Y.; Dai, Y.; Guo, M.; Niu, C.; Lu, J.; Huang, B. Electronic and magnetic properties of perfect, vacancy-doped, and nonmetal adsorbed $\mathrm{MoSe}_{2}, \mathrm{MoTe}_{2}$ and WS 2 monolayers. Phys. Chem. Chem. Phys. 2011, 13, 15546-15553. [CrossRef]

22. Sakthivel, M.; Ramaraj, S.; Chen, S.M.; Chen, T.W.; Ho, K.C. Transition-metal-doped molybdenum diselenides with defects and abundant active sites for efficient performances of enzymatic biofuel cell and supercapacitor applications. ACS Appl. Mater. Interfaces 2019, 11, 18483-18493. [CrossRef] [PubMed]

23. Falola, B.D.; Fan, L.; Wiltowski, T.; Suni, I.I. Electrodeposition of Cu-doped $\mathrm{MoS}_{2}$ for charge storage in electrochemical supercapacitors. J. Electrochem. Soc. 2017, 164, D674-D679. [CrossRef]

24. Zhang, M.; Wu, J.; Zhu, Y.; Dumcenco, D.O.; Hong, J.; Mao, N.; Deng, S.; Chen, Y.; Yang, Y.; Jin, C.; et al. Two-dimensional molybdenum tungsten diselenide alloys: Photoluminescence, Raman scattering, and electrical transport. ACS Nano 2014, 8, 7130-7137. [CrossRef] [PubMed]

25. Bhat, K.S.; Nagaraja, H.S. Effect of isoelectronic tungsten doping on molybdenum selenide nanostructures and their graphene hybrids for supercapacitors. Electrochim. Acta. 2019, 302, 459-471. [CrossRef] 
26. Ambrosi, A.; Sofer, Z.; Pumera, M. 2H $\rightarrow 1 \mathrm{~T}$ phase transition and hydrogen evolution activity of $\mathrm{MoS}_{2}, \mathrm{MoSe}_{2}, \mathrm{WS} 2$ and WSe strongly depends on the MX 2 composition. Chem. Commun. 2015, 51, 8450-8453. [CrossRef]

27. Pazhamalai, P.; Krishnamoorthy, K.; Mariappan, V.K.; Sahoo, S.; Manoharan, S.; Kim, S.J. A high efficacy self-charging MoSe 2 solid-state supercapacitor using electrospun nanofibrous piezoelectric separator with Ionogel electrolyte. Adv. Mater. Interfaces 2018, 5, 1800055. [CrossRef]

28. Qi, K.; Hou, R.; Zaman, S.; Qiu, Y.; Xia, B.Y.; Duan, H. Construction of metal-organic framework/conductive polymer hybrid for all-solid-state fabric supercapacitor. ACS Appl. Mater. Interfaces 2018, 10, 18021-18028. [CrossRef]

29. Karade, S.S.; Dubal, D.P.; Sankapal, B.R. Decoration of ultrathin $\mathrm{MoS}_{2}$ nanoflakes over MWCNTs: Enhanced supercapacitive performance through electrode to symmetric all-solid-state device. ChemistrySelect 2017, 2, 10405-10412. [CrossRef]

30. Yang, B.; Hao, C.; Wen, F.; Wang, B.; Mu, C.; Xiang, J.; Li, L.; Xu, B.; Zhao, Z.; Liu, Z.; et al. Flexible black-phosphorus nanoflake/carbon nanotube composite paper for high-performance all-solid-state supercapacitors. ACS Appl. Mater. Interfaces 2017, 9, 44478-44484. [CrossRef] [PubMed]

31. Krishnamoorthy, K.; Pazhamalai, P.; Veerasubramani, G.K.; Kim, S.J. Mechanically delaminated few layered $\mathrm{MoS}_{2}$ nanosheets based high performance wire type solid-state symmetric supercapacitors. J. Power Sources 2016, 321, 112-119. [CrossRef]

32. Liu, F.; Zeng, L.; Chen, Y.; Zhang, R.; Yang, R.; Pang, J.; Ding, L.; Liu, H.; Zhou, W. Ni-Co-N hybrid porous nanosheets on graphene paper for flexible and editable asymmetric all-solid-state supercapacitors. Nano Energy 2019, 61, 18-26. [CrossRef]

33. Hu, M.; Li, Z.; Li, G.; Hu, T.; Zhang, C.; Wang, X. All-solid-state flexible fiber-based MXene supercapacitors. Adv. Mater. Technol. 2017, 2, 1700143. [CrossRef] 